\title{
Supervision register in practice
}

\author{
Phillip J. Vaughan
}

\begin{abstract}
A sample of 19 consultant psychiatrists and 28 keyworkers were interviewed to defermine their views on using the supervision register and to see whether it was affecting their practice. The majortty felt that the supervision register was politically mottvated and had little effect on direct clinical practice. However, there was a slight increase in indirect patient activities such as administration and meetings and some keyworkers were more vigorous in their outreach work. Most patients dild not challenge their registration and the use of advocates in Care Programme Approach meetings may be needed. There was also a need for improved training and supervision for keyworkers.
\end{abstract}

The introduction of the supervision register in April 1994 produced a rather jaundiced response from the Royal College of Psychiatrists. It was felt that a mechanism to document a small group of vulnerable patients in the community would have little clinical utility. There were fears that it would prove costly, be time consuming to administer and have an adverse effect on the therapeutic relationship. Furthermore, it was felt that there would be a strong disincentive for consultant psychiatrists to include patients on the register and for other mental health professionals to become keyworkers (Caldicott, 1994).

A postal survey by Vaughan (1996) 12 months after its introduction showed that although the register had been absorbed organisationally it was less accepted professionally. To test the latter finding a study was undertaken to determine the views and attitudes of staff using the register and to see whether they felt it was affecting their professional practice.

\section{The study}

The returns from the postal survey were used to select a group of consultant psychiatrists for interview. The sample was limited to consultants who were individually identified in the survey, had between two and six registrations at 31 March 1995 and were located within a 75 mile radius of the researcher's base. Those with only one or nil registrations were excluded on the basis that they may not have been fully committed to using the register. Those with more than six registrations were excluded as it was felt that they may have been less discriminating in the selection of suitable patients. Accordingly, the 36 consultants identified in this way were invited to take part in the study.

A semi-structured interview schedule was designed to elicit their views on the usefulness of the register in the light of experience, and on the impact it had on their practice. Finally, those interviewed were asked to volunteer the names of the keyworkers for their registered patients who could be approached to be inteviewed in a similar manner.

\section{Findings}

Of the 36 consultants invited to take part in the study, 19 agreed to be interviewed. Ten National Health Service trusts were represented with their mental health provider units covering rural, urban and inner-London areas. On 31 March 1995 this group of consultants had 68 registered patients between them. At the time of the interview, between 6 months and 15 months later, their total registrations amounted to 65 . Only one consultant had exceeded the original limit of six registrations which had included him in the study, although two consultants had reduced to only one and one had none.

Of the 29 keyworkers volunteered by the consultants 28 were interviewed, consisting of 20 community psychiatric nurses, six social workers, one occupational therapist and one general practitioner. Together they supervised a total of 48 registered patients (mean 1.7 patients). Their length of post-qualification mental health experience ranged from 3-31 years (mean 13.4 years).

\section{Attitudes and feelings}

Only four of the consultants had a positive view of the register. Most felt antagonistic, sharing a feeling that it was 'policing by the back door' and 'a political ploy'. Anxiety about civil liberties was also an issue. About a third (6) were unhappy about the name 'supervision register' and felt that it smacked of authority.

Slightly more keyworkers, about a third (9), had a positive view of the register but the rest shared the consultants' views. A greater proportion (17) were unhappy about its name and felt that it was 'stigmatising', and 'misleading'. Over two-thirds (20) felt uncomfortable about under- 
taking the role of keyworker. For many workers, anxiety levels were raised and fears of being victimised if things went wrong were commonplace.

Over half (10) of the consultants found the three risk categories simplistic, with eight being particularly unhappy with the category of 'significant risk of suicide'. The views frequently expressed were that many patients moved in and out of this category too frequently to make it meaningful. In any event it was felt that if there was a serious risk of suicide the patient needed treatment rather than supervision in the community.

\section{Effects on patients}

Of the 65 patients registered, only five examples were quoted of there being an objection to registration with only two having sought advice (Citizens' Advice Bureau 1, solicitor 1). The remainder were said to have been 'surprisingly benign', 'didn't mind', 'bemused', or simply 'didn't understand it'. However, many consultants had taken care to present the registration in a positive light, explaining that they would benefit from priority of care.

No extra resources had been produced for these patients, although two examples of extra money becoming available for clerical time and computer equipment to run the system were quoted. Conversely, there were no reported adverse effects of registration in terms of the patients being denied access to other resources. Indeed, keyworkers occasionally reported that supervision register patients had easier access to in-patient beds when beds were otherwise scarce.

\section{Effects on practice}

Patient contacts with consultants were virtually unaffected by registration. Only three consultants reported that they were more diligent about communication with others and only one saw the patient more frequently than he would otherwise have done. The general feeling expressed was that the services were responsive to the patients needs whether or not registration had taken place. Notwithstanding, almost half (8) acknowledged that reviews occurred more frequently than they otherwise would.

As with consultants, keyworkers reported little difference in the amount of contact time with patients. Only four saw them more fequently than 'normal'. Nevertheless, over a third (10) acknowledged being more diligent about following up missed appointments, recording information and liaising with others.

Just over half (11) of the consultants reported that up to half an hour extra per week was needed for paperwork and just under half (8) reported that an extra half hour per week was needed for meetings. Keyworkers were affected less, with nine needing an extra half hour per week on paperwork and four needing an extra half hour in meetings. One further keyworker spent an extra one hour per week on each.

Just over one-third (10) of keyworkers had received specific training on suicide risk/management (average 2.8 days) and a quarter (7) on assessing the risk of violence.

Finally, one-quarter received no formal supervision of their work relying on informal consultation with their peers and the consultant psychiatrist.

\section{Comment}

The median number of registrations per consultant at interview compared with 31 March 1995 remained constant at 3.5, which may indicate that the system is already settling down to a steady state.

Although there was no deliberate strategy among the mental health teams to single out nurses as keyworkers, the findings support the view of McEvoy (1996) that although any mental health professional may be designated as a keyworker, in practice the majority will be community psychiatric nurses (CPNs). This is perhaps not surprising, given that most registered patients will already have contact with a CPN for the administration of medication. Furthermore, in the sample group CPNs had twice the length of post-qualifying experience as social workers, their nearest rivals (i.e. a mean of 14.9 years as opposed to a mean of 7.5 years).

\section{Attitudes and feelings}

Experience of using the register has clearly not ameliorated the considerable concern which was expressed by psychiatrists when the proposals to establish it were first made. At that time most professionals were reported to be either indifferent or hostile which, apart from the then proposed supervised discharged arrangements, was regarded as the most controversial Government initiative within the mental health field (Holloway, 1994). Indeed, it was the expressed indignation of so many of its Members that led the Royal College of Psychiatrists to challenge the Secretary of State for Health over its introduction (Caldicott. 1994).

This research shows that predominantly negative feelings about the supervision register remain. This should be cause for concern. bearing in mind that the consultant sample potentially represented the most judicious users of the system. It was clear that consultants and keyworkers were using the supervision register 
under a sense of obligation rather than because they had a belief in or enthusiasm for it.

Furthermore, the frequently stated dislike for the name 'supervision register' supports the view of Haghighat (1994), who felt that the term could add suspicion to delusional patients and reduce the acceptability of psychiatric services. There was some support for the 'softer' title of 'support register' which many felt more comfortable with as it deflected the pure policing aspects of the professional role. Keyworkers in particular were uncomfortable about the latter. The discomfort of having what Harrison \& Bartlett (1994) refer to as a duty of care over a patient who probably does not want to see them was commonplace.

If this sample represents 'the best' views, what of those who do not use the register as reported by Vaughan (1996)? It is possible that some credibility may be gained by restricting the registration category to only those who are at risk of violence to others as has already been done in several London National Health Service trusts (McCarthy et al, 1995).

\section{Effects on patients}

The fact that so many patients failed to react adversely to being told that they were being put on the register may be due to the reported positive way in which it was represented. More likely, however, is the fact that by definition supervision register candidates are the most damaged and mentally debilitated by their illness. Their long association with the psychiatric services, multiple admissions to hospital and detention under section will have blunted their ability to question the procedure. It is important, therefore, that in any discussion with the patient where registration is being considered, care is taken to ensure that the patient is accompanied by an advocate or informed friend or relative. This would seem particularly important in order to address the civil liberties issues as there is no formal right of appeal.

The feared negative results of registration prejudicing the patient's opportunities for access to resources as quoted by Quinn (1995) were not evident. Indeed, the keyworkers quoted some instances where priority of care was demonstrated by having access to in-patient beds previously denied to them.

\section{Effects on practice}

The direct service to the patient appears to have been virtually unchanged as a result of registration. The overwhelming claim was that the service was responsive to the patients' needs rather than as a response to what was seen as a bureaucratic dictat. Indirect and non-clinical activities, however, were affected in many in- stances in terms of more frequent reviews, more pro-active communication and better tracking of patients. However, even though almost half of the patients were reviewed more frequently, the extra time demanded in meetings and administration was fairly small, at less than half an hour extra per week for each. It appeared that the big increase in these activities had already occurred as a result of the implementation of the Care Programme Approach. The evidence from this survey does not support the fears of a massive increase in these activities as a result of the introduction of the supervision register expressed by the College (Caldicott, 1994).

Although the keyworkers in the sample were a very experienced group of staff, there was a clear gap in their training in relation to risk assessment and management. Furthermore, regular formal supervision was not available to all staff. In view of the vulnerability of the patients concerned and the keyworker's exposure to high levels of risk, it would seem crucial for all such staff to receive adequate training in these areas. Similarly, it is unreasonable and unsafe to expect staff to act as keyworkers without appropriate supervision.

\section{Conclusions}

Many consultant psychiatrists expressed indignation that the supervision register had been imposed upon them. Most saw it as a political response to public disquiet over the much publicised tragedies involving the mentally ill in the community which added nothing to good clinical practice. The majority of keyworkers, on the other hand, had similar reservations but also had greater feelings of anxiety over being scapegoated if things went wrong.

There is a danger, therefore, that the supervision register will become a token response to satisfy a bureaucratic need rather than being seen as a useful procedural tool in the treatment of the seriously mentally ill in the community. Additionally, there would appear to be some support for restricting registration only to those patients who are at risk of harming others, which many feel was the group that caused all the concern in the first place.

The fact that so many patients meekly accepted registration is likely to indicate their disinterest or inability to challenge the mental health system. There would seem to be a strong case for an advocate to attend every Care Programme Approach meeting where the use of the supervision register is being considered.

Although the actual clinical care of patients was unaffected by registration, they were more likely to be subject to more vigorous outreach work by their keyworkers. In that sense the 
supervision register could be said to be achieving its aims where this has occurred. Conversely, the resultant impact on staff time for additional meetings and administration was fairly small.

Finally, there is a need for greater training for keyworkers in risk management together with close supervision to ensure a good service to patients and to provide support to the staff.

\section{References}

CaldicotT, F. (1994) Supervision registers: the College's response. Psychiatric Bulletin, 18, 385-388.

HAGHIGHAT. R. (1994) Support registers instead of supervision registers (letter). Psychiatric Bulletin 18. 774

HARRISON, G. \& BARTLETT, P. (1994) Supervision registers for mentally ill people. British Medical Joumal, 309. 551552.
HoLLOWAY, F. (1994) Supervision registers: recent government policy and legislation. Psychiatric Bulletin. 18, 593-596.

MCCARTHY, A., Roy, D., Holloway, F. et al (1995) Supervision registers and the Care Programme Approach: a practical solution. Psychiatric Bulletin. 19, 195-199.

McEvoy, P. (1996) Supervision registers: implications for key workers. Mental Health Nursing. 16(4), 8-10.

GUinN, J. D. (1995). Supervision registers. Psychiatric Bulletin, 19, 513.

VAUGHAN, P. J. (1996). The supervision register: one year on. Psychiatric Bulletin. 20, 143-145.

Phillip J. Vaughan, Project Manager, Forensic Project Team, The Wessex Consortium, Highcroft, Romsey Road. Winchester, Hampshire SO22 5DH

\section{Section 17 of the Mental Health Act}

John Milton

From 1 April 1996 mental health legislation was expanded to include provision for "supervised discharge" under the Mental Health (Patients in the Community) Act 1995. However, the use of Section 17 (s17) of the Mental Health Act has always provided an option for an extended leave. This retrospective case note study examines 10 years of practice of $\$ 17$ use and focuses on characteristics of those patients recalled. increases in 817 applications represented equivalent increases in admissions and overall sections, although numbers of patients actually recalled had fallen significantly. Patients recalled affer discharge were generally middle-aged men with a long history of schizophrenia, on s3, who relapse quickly due to treatment non-compliance.

Prior to the final introduction of the 1995 Mental Health (Patients in the Community) Act, the question of community supervision and treatment orders was widely debated in the Bulletin (Turner, 1994), within the Royal College of Psychiatrists, and within the Department of Health's own review of legal powers on mentally ill people in the community which preceded the Bill (Pease \& Reed, 1993). Many of the arguments recommending compulsory community treatment had been considered and rejected because of the prediction that compulsory treatment would contravene Article 5.1 of the European Convention of Human Rights. For example, simply stopping treatment without deterioration may not be seen as objective medical evidence of mental disorder sufficient for compulsory treatment. None the less, following the publication of the Royal College of Psychiatrists' report Community Supervision Orders (Royal College of Psychiatrists, 1993) suggesting expanded legislation for supervised discharge and extended leave, a survey of general psychiatrists was generally supportive of the changes (Hampson \& Davison, 1994).

In addition to the newer supervised discharge, leave of absence (s17, Mental Health Act, 1983) is that part of the Act already in use by which the responsible medical officer (RMO) formally grants leave outside the hospital, though the patient 